\title{
Intersecções e identidades na docência do direito no Brasil*
}

\author{
Maria da Gloria Bonelli** \\ Patricia Tuma Martins Bertolin*** \\ Rossana Maria Marinho Albuquerque**** \\ Veridiana P. Parahyba Campos***** \\ \& Renne Martins Barbalho***
}

Resumo: $\mathrm{O}$ artigo analisa as mudanças na docência do direito, relacionando a maior participação das mulheres e da diferença no professorado, com a pulverização das instituições de ensino, a distribuição regional, os regimes de trabalho e o maior de grau de titulação docente. Investiga como esses deslocamentos se refletem nas identificações profissionais e em suas intersecções, bem como no jogo para produzir o centro e o descentramento dos grupos estabelecidos e do cânone jurídico. Baseia-se em dados do Censo Nacional da Educação Superior, Inep (2015) e em entrevistas qualitativas realizadas com docentes homens e mulheres de seis faculdades de direito do país.

Palavras-chave: Profissionalismo. Docência do direito. Diferença. Intersecções. Identidades.

\section{Intersections and identities in the Brazilian legal academy}

Abstract: The article focuses on the changes in legal academy in Brazil, linking the increase in the participation of women and difference among the professoriate, with the fragmentation of institutional models, regional distribution of schools, type of labor agreement and higher titration of faculty members. It examines how such dislocations are articulated with professional identifications and their intersections, as well as the play to produce the center and to decenter the canonical knowledge and established groups. The research gathers data from the $2015 \mathrm{Na}$ tional Census of Higher Education, Inep, and from qualitative fieldwork, interviewing male and female professors of six Brazilian Law schools.

Keywords: Professionalism. Legal teaching. Difference. Intersections. Identities.

\section{Introdução}

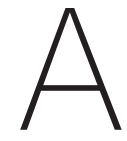

expansão dos cursos de direito é conhecida na literatura sobre o ensino jurídico no Brasil (Observatório do Ensino do direito, FGV-SP). Na década de 1990, o número de cursos privados salta, gerando impacto no mercado docente. Segundo Geller (2012: 10), em 1991 havia 165 cursos de direito no Bra-

\author{
* A investigação \\ contou com \\ auxílio pesquisa da \\ Fapesp (processo \\ 2016/08850-1) e \\ do CNPq (processos \\ 443416/2015-0 e \\ 303364/2015-7). Teve \\ o apoio de Bruna \\ Verdadeiro Moraes, \\ com Bolsa Fapesp de \\ Treinamento Técnico \\ I. Agradecemos \\ a assessoria da \\ Profa. Fabiana \\ Luci de Oliveira no \\ processamento \\ dos dados e na \\ construção de \\ tabelas.

** Maria da
Gloria Bonelli é
professora sênior
do Departamento
de Sociologia da
Universidade Federal
de São Carlos
(UFSCar), São Carlos,
São Paulo, Brasil.
Orcid: 0000-
0003-3877-9825.
<gbonelli@uol.com.
br>.
*** Patricia Tuma
Martins Bertolin
é professora do
Programa de
Pós-Graduação
em Direito Político
e Econômico da
Universidade
Presbiteriana
Mackenzie, São
Paulo, São Paulo,
Brasil.
Orcid: 0000-
0002-3835-829x.
<ptmb@uol.com.
br>.
**** Rossana
Maria Marinho \\ Maria Marinho
}


Albuquerque é professora adjunta de sociologia do Departamento de Ciências Sociais da Universidade Federal do Piauí (UFPI), Teresina, Piauí, Brasil. Orcid: 00000002-6199-1392. <rossanamarinho@ yahoo.com.br>

\section{***** Veridiana P.} Parahyba Campos é doutora em sociologia pela Universidade Federal de Pernambuco (UFPE), Recife, Pernambuco, Brasil. Bolsista da Fundação Carlos Chagas.

Orcid: 0000-00030014-754X $<$ veridianacampos 01@gmail.com>.

****** Renne Martins Barbalho é doutora em sociologia pela Universidade Federal de São Carlos (UFSCar), professora voluntária na Universidade de Brasília (UnB) e no Mestrado Internacional em Gestão de Empresas - Ibrap/Universidade Lusófona de Humanidades e Tecnologias de Lisboa, Portugal. Orcid: 0000-00019052-2010. <rennemartins barbalho@gmail. com>.

1. Mais adiante, discorreremos detidamente sobre os dados do campo (tópico 3). sil; dez anos depois, em 2001, esse total havia subido para 380 cursos e, em 2004, chegaram a 733. Os dados do Censo da Educação Superior (Inep) de 2015 indicam que o total de cursos de direito é de 1.171 .

Essa multiplicação é vista como perda de qualidade do ensino e do profissional formado nesses cursos, além da precarização da atividade docente desses estabelecimentos. O estudo aqui desenvolvido reflete sobre as formas como tal proliferação produziu fragmentação nos modelos institucionais e na diversificação do corpo de professores, reverberando nas lutas para produzir o centro e para descentrar a docência do direito. A padronização costuma acompanhar os diagnósticos da massificação desses cursos, e os dados aqui reunidos procuram dar visibilidade também ao que escapa ao enquadramento da reprodução, deslocando a profissão de sua posição fixa e central nas experiências e identificações de seus membros.

Metodologicamente, o trabalho analisa dados quantitativos do Censo da Educação Superior de 2015 sobre os docentes, os discentes e os cursos de direito no Brasil e apresenta os primeiros resultados das entrevistas qualitativas que estão sendo realizadas com professores dos cursos de direito de seis instituições de ensino superior, com alguma diversidade territorial e regional, com formatos administrativos e organizacionais variados, seja por serem privadas ou públicas, de maior ou menor porte, com ou sem pós-graduação stricto sensu. Quanto aos docentes entrevistados, buscou-se uma distribuição além de distintos regimes de trabalho, graus de formação e perfil demográfico. O total de entrevistas disponíveis é de 53, tendo em vista que o trabalho de campo continua em andamento.

Em sua dimensão qualitativa, foram realizadas entrevistas semiestruturadas, apoiadas em um roteiro que orientou as cinco pesquisadoras visando obter uma referência comum de investigação, como também espaço para as questões que surgissem no processo de interação com as entrevistadas e entrevistados. Houve solicitação para a realização das entrevistas nas instituições através de coordenações, chefias ou direção. Os docentes foram contatados por e-mail ou presencialmente e aqueles que aceitaram participar também indicaram outros colegas - como na técnica da bola de neve. Houve consentimento para a gravação das entrevistas com compromisso de não se identificar os participantes nem nomear as instituições. Em sua dimensão quantitativa, obtidos os dados referentes exclusivamente à graduação em direito, eles foram selecionados de acordo com os objetivos da investigação, sendo processados em SPSS para proceder aos cruzamentos de variáveis. A construção de tabelas e gráficos foi feito no Excel, e alguns deles foram incorporados neste artigo ${ }^{1}$. 
A proliferação dos cursos de direito nos estabelecimentos de ensino superior privados foi acompanhada do predomínio da lógica empresarial sobre a lógica profissional, resultando num modelo híbrido e fragmentário. A organização do trabalho profissional articula a obtenção de uma formação universitária - para o domínio de uma área do saber por meio do conhecimento abstrato - com o controle de mercado pelos pares. Essa lógica é sustentada no ideário da prestação de serviços especializados com qualidade, além de autonomia da expertise em relação aos interesses do Estado, do mercado e do cliente. A lógica dos negócios que dá embasamento ao ensino superior privado se nutre do discurso da livre concorrência, que é crítica ao fechamento e à proteção de mercado - como no profissionalismo -, mas conta com apoio financeiro do Estado, sem vê-lo como intervenção no mercado. O Estado, por sua vez, opera em torno da lógica burocrática, que dá mais valor à eficiência e às relações verticalizadas de comando e execução, do que às relações horizontais mais características aos pares profissionais. Se o avanço do conhecimento é o maior valor na expertise, a relação entre custo e benefício predomina na gestão gerencial das organizações e da burocracia².

A participação das mulheres no ensino do direito decorre do deslocamento do modelo profissional dominante até então, que ao construir monopólios de mercado também fecha o espaço para quem ingressa mais tarde na atividade. A hibridização do profissionalismo com a lógica empresarial e organizacional, junto com o crescimento de posições disponíveis, diversificou o perfil social dos docentes nos cursos jurídicos.

A nova composição da docência do direito tem uma história a ser contada, tanto sobre a conquista feminina de posições nessa carreira, como sobre as idas e vindas do longo processo de deslocamento do corpo acadêmico "normásculo" (Chabaud-Rychter et alii, 2014), dando expressão às diferenças.

Para essas autoras, "normásculo" remete ao papel histórico dos discursos científicos dominantes em tornar invisíveis as questões de gênero na produção do conhecimento. Sem perceber, impregnam de masculinidade teorias e resultados considerados como neutros e objetivos, mostrando indiferença às desigualdades e ao domínio dos homens sobre as mulheres (Chabaud-Rychter et alii, 2014: 3).

Processo semelhante ocorreu nas faculdades de direito, cujo ingresso feminino no corpo discente tornou-se maioria do alunado, mas não teve o mesmo resultado na composição do professorado. A inclusão das mulheres e da diferença na docência ganhou expressão recentemente, mas elas devem lidar com a ideologia profissional da neutralidade do conhecimento e do cânone dos grupos estabelecidos. 
Enquanto a presença de profissionais com marcas sociais distintas foi ínfima, elas e eles buscaram apagar as diferenças que os subalternizam, aderindo a tal ideário até mesmo na corporalidade. Neste sentido, dar visibilidade à diferença dos corpos, dos cabelos, do vestir faz parte desse descentrar do padrão dominante, das cores neutras dos terninhos, da "discrição" que apaga registros dissonantes, pluralizando a diversidade na aparência e atuando para que outras imagens sejam reconhecidas como profissionais.

Por outro lado, com o adensamento dos marcadores da diferença entre os docentes, a visibilidade do feminino e da diversidade passou a ser vocalizada por aqueles e aquelas que se identificavam não só com a profissão, mas também com sua condição de gênero, de sexualidade, sua condição étnico-racial e de classe, descentrando a produção teórica concentrada nos modelos analíticos neutros e nos conceitos que sustentavam essas abordagens. Novas perspectivas elaboradas por homens e mulheres, brancos e não brancos, heterossexuais e homoafetivos, dos grupos privilegiados e de origem social desfavorecida, provenientes das Regiões Norte ou Sul têm contribuído para deslocar a produção canônica de conhecimento (Connell, 2012).

Os indicadores quantitativos de alguns aspectos dessa mudança estão no Censo Nacional de Educação Superior do Instituto Nacional de Estudos e Pesquisa (Inep). Segundo os dados referentes aos cursos de direito, em 2015 havia 32.249 docentes, sendo $60 \%$ homens. Dos 23.735 docentes para os quais havia informação quanto à cor/raça, 22,7\% eram de pardos, pretos e indígenas. Do total de cursos de direito, $14,2 \%$ são públicos ou especiais, $46,4 \%$ são privados sem fins lucrativos e $39,4 \%$ de privados e com fins lucrativos.

O artigo apresenta a interseç̧ão entre gênero e cor/raça com o grau de titulação, localização regional, o tipo de instituição e o regime de trabalho. Tem por objetivo mostrar que a interseccionalidade tanto contribui para descentrar o ensino do direito, como para produzir a estratificação profissional, reordenando diferenças e desigualdades sem erradicá-las. Entende que a fragmentação dos modelos institucionais e a variação do perfil docente geram oportunidades e constrangimentos distintos, burilados pelos professores que constroem suas carreiras cotidianamente, com respostas que escapam aos padrões. Apesar de serem várias as formas de estratificação na docência, a que separa a pós-graduação stricto sensu da graduação estabelece uma clivagem evidente quanto às condições profissionais.

A pesquisa mapeou deslocamentos na produção do conhecimento, no conteúdo do profissionalismo, na fragmentação institucional e no perfil docente. Produzir o 
centro e seu descentramento é um jogo continuado, uma incessante negociação de sentidos, nos enfrentamentos morais e na diversidade de valoração entre os profissionais. Assim, há docentes que se percebem como "ilhas", lecionando e difundindo seu conhecimento na instituição como múltiplos focos endógenos de expertise e inovação, sem uma nucleação centralizadora a predominar nesse mundo. Há os que querem fazer parte do que consideram mais valorizado, ser docente da pós-graduação, e contribuem para a construção desse espaço, a partir de fora. Há aqueles que fazem parte da pós-graduação, mas se sentem deslocados por acumularem outras ocupações, sendo interpelados por essas identidades. Outros se percebem descentrados na relação com as abordagens canônicas, sejam as jurídicas ou as acadêmicas. O centro é mais uma identificação atribuída do que uma concepção de si mesmo, dando alma ao jogo, aos embates em torno do que é ser bom ou boa docente. É também uma posição situacional, fluída em vez de fixa, na qual um mesmo docente pode se sentir parte do centro e excluído dele. Pode se ver com autoridade na condição de gestor universitário, e desprestigiado por não ser credenciado na pós-graduação ou, ao contrário, com influência como coordenador de mestrado, mas sem a respeitabilidade da carreira jurídica pública de um magistrado.

Na perspectiva profissional, destaca-se a passagem do predomínio do profissionalismo ocupacional para a presença do profissionalismo organizacional. No primeiro, o grupo profissional valoriza a expertise, o conhecimento específico que dá identificação, orienta a ação e as normas comuns da profissão. O segundo é acionado como uma ideologia pelos gestores e pelas corporações para produzir comportamentos no grupo, disciplinando-o e controlando-o de cima para baixo. Os múltiplos usos do profissionalismo diluem as fronteiras que as profissões tradicionais construíram para preservar sua autonomia frente aos negócios empresariais e à lógica administrativo-gerencial.

Na dimensão da fragmentação dos modelos institucionais, tais deslocamentos podem gerar mais oportunidades, diversidade e distanciamento do ensino jurídico estabelecido, tanto em seu conteúdo como em sua avaliação, seja pela perda de qualidade, pela conversão em negócio com fins lucrativos, seja pela amplitude das formas de conceber o direito como conhecimento. Essas evidências sustentam o argumento de que os modelos dominantes de profissionalismo jurídico e de professor de direito têm de lidar com as modificações no professorado, com a estratificação da docência, com as práticas empresariais, que concebem alunos como clientes e com o controle administrativo das atividades docentes.

A nova composição social docente mostra a diferença nos corpos vistos pelos alunos à frente das disciplinas nas salas de aula, dando visibilidade ao que antes não era 
percebido como possível. Nesse sentido, os descentramentos também são identitários (Hall, 2000), incorporam os deslocamentos da experiência à própria identificação, podendo interseccionar a profissão, com o gênero, a cor/raça, a origem social, a sexualidade, a geração, na forma como os docentes compreendem sua trajetória profissional. Nas entrevistas qualitativas, observa-se que, mesmo quando os discursos constroem explicações naturalizadas ou essencializadas sobre a diferença, elas são vivenciadas subjetivamente, gerando hibridismos.

Para além das disputas entre credencialismo profissional, empresários do ensino do direito, Ministério da Educação, docentes e discentes há a incorporação de novos sujeitos na docência envolvidos no jogo para a produção de centros e para descentrá-los, diluindo essas posições como fixas. A visibilidade das mulheres e, em menor proporção, das minorias, expande a diversidade na profissão e os referenciais para o corpo discente, construindo novos exemplos por meio de orientações e tutorias.

A pesquisa registra a expansão dessa diversidade e dos deslocamentos que a acompanham, entendendo que as mudanças observadas não resultam de determinismos que reduzem os sujeitos às marcas que portam como gênero, cor/ raça, sexualidade. Ao contrário, entende que é do hibridismo, do encontro e do embate das diferenças que surgem as abordagens dissonantes que descentram o saber canônico. Elas podem ser produzidas por mulheres e homens, por negros e brancos, por heterossexuais ou homoafetivos, que partilham conhecimentos elaborados em relações distintas daquelas que marcaram as concepções hegemônicas.

O ensino jurídico praticado por estes docentes tornou-se uma área de produção acadêmica bem vasta no Brasil e na América Latina, refletindo o tamanho do campo. A diversificação dos estudos e pesquisas sobre o tema, com múltiplas perspectivas contempladas, é um indicador de como o processo fragmentário está presente nessa especialização do saber que se constitui com alguma autonomia, enfrentando seus embates em torno do que foi um cânone mais hegemônico e hoje examina a estrutura curricular, disciplinas e metodologias, pedagogias como ainda pluralismo jurídico, pensamento contra-hegemônico e outros temas (Veronese, Farranha \& Felix, 2018; Wolkmer \& Lippstein, 2017; Caovilla \& Fagundes, 2016; Feferbaum \& Ghirardi, 2012; Ghirardi \& Feferbaum, 2013).

Há associações que articulam as problemáticas do ensino do direito, publicando trabalhos, livros, organizando congressos, focalizando metodologias, pesquisa empírica em direito. Na impossibilidade de sistematizar neste artigo tal expertise 
- que foca a docência como profissão, mas não os conteúdos, a produção de saber e a relação ensino-aprendizagem -, recortamos apenas o aspecto do ensino jurídico no que respeita à diversificação social docente e como a presença feminina é percebida ou tornada invisível no curso de direito.

Especificamente sobre isso há a recente pesquisa desenvolvida na Faculdade de Direito da USP sobre o currículo oculto nas interações de gênero nas salas de aula. A investigação coordenada por Neder Cerezetti et alii (2019) identificou as dinâmicas de gênero nas relações entre as alunas e os alunos e entre estas e estes e as professoras e os professores, bem como a convivência dos docentes entre si. A naturalização da autoridade e da presença masculina na docência contrasta com o estranhamento e reconhecimento do feminino, esperando comportamentos mais lineares delas, enquanto eles transitam com facilidade entre o afeto e a rigidez. Para as autoras, as sutilezas nas diferenças de comportamento em relação a homens e mulheres na sala de aula mostram que o marcador de gênero está oculto, o que torna a discriminação mais difícil de ser percebida e enfrentada.

Como vem ocorrendo em pesquisas com esse tipo de recorte e problema (Deo, 2019), as diferenças e desigualdades de gênero na vida acadêmica do direito constituem menos situações de discriminação aberta e mais de viés implícito a desvalorizar o que é feminino, homoafetivo, negro, produzindo privilégios para o masculino, o hétero, o branco. As desvantagens sutis para as mulheres, desde sua entrada na área, vão potencializando discriminações interseccionais quando isso é entrecortado por outras marcas de diferenças, como a cor/raça e a sexualidade.

\section{Profissionalismo, gerencialismo e identificações na docência do direito}

Margaret Thornton (2015) analisou a articulação entre o regime de gênero ${ }^{3}$ e o neoliberalismo no mundo acadêmico do direito na Austrália. Segundo a autora, o pilar desse regime é a ideologia do mérito; sua suposta neutralidade obscurece a preferência pela masculinidade que acompanha o modelo da "melhor pessoa para o trabalho". A virada neoliberal nas universidades, orientada pela lógica gerencial das corporações e dos negócios teria proporcionado novo gás aos critérios normásculos que direcionam o ensino, a pesquisa, a extensão, a gestão e as demais atividades acadêmicas, reconfigurando o regime de gênero, em um contexto no qual as mulheres já representavam $56 \%$ da docência do direito.

Ela entende que, nos anos 1980 e 1990, o ideário da justiça social encontrava-se em ascensão e as universidades estavam mais abertas às políticas de inclusão,

\footnotetext{
3. Raewyn Connell (2006) referese ao regime de gênero como parte integrante do local de trabalho a partir de um estudo de dez organizações do setor público na Austrália. A autora constrói uma abordagem multidimensional de gênero, mostrando as limitações do conceito de teto de vidro, que pensa gênero como duas categorias fixas de pessoas. O ponto de partida apresentado é que as instituições são genderizadas e que políticas de igualdade para superação do teto de vidro concebem essas administrações como independentes de gênero. Ela destaca quatro dimensões do regime de gênero:

1. divisão do trabalho segundo o gênero;

2. relações de poder e as hierarquias de autoridade segundo o gênero;

3. relações humanas e emoções nas organizações; e 4. cultura de gênero e simbolismo no ambiente de trabalho.
} 
observando-se agora o retrocesso desse cenário, apoiado na ideologia do mérito e da "escolha" das mulheres pela dedicação às crianças em detrimento do avanço profissional. Para Thornton, o mito da objetividade do mérito esconde elementos inegáveis de "reprodução homossocial", apoiado na dimensão subjetiva do processo de seleção sobre quem se "encaixa" ou não na cultura do ambiente do trabalho. Tanto a construção do mérito como o regime de gênero não são estáticos e se ajustam a contextos distintos. Com o predomínio da lógica gerencial e de negócio nas universidades, os professores foram perdendo força enquanto grupo e o ensino foi ficando mais feminizado. No modelo universitário neoliberal, as funções de gestão e avaliação acadêmica ganharam poder e prestígio, masculinizando-se ao serem ocupadas pelos docentes que conseguiam viabilizar suas ambições de carreira.

Hilary Sommerlad (2015) analisa como o mérito - por ser fluido, contingente e instrumental - foi construído como neutro e objetivo mediante uma "mágica social" que reflete as relações sociais dominantes e o poder das elites das profissões jurídicas na Inglaterra e no País de Gales, atribuindo à excelência profissional os padrões masculinos e ao mérito as práticas informais racializadas. Desta forma, reproduz-se a hegemonia dos homens brancos de classe média alta na profissão, como resultado legítimo e justamente merecido de seus privilégios sistemáticos, com a inclusão subalternizada da diversidade.

Ao pensar o conceito do profissionalismo diante do predomínio da lógica das organizações que se globalizam e do gerencialismo que acompanha esse padrão, Julia Evetts (2012) procurou diferenciar a forma como o profissionalismo foi construído enquanto valor normativo partilhado pelo grupo ocupacional (profissionalismo ocupacional) do tipo de visão de mundo organizacional, que ressignifica esse ideário por meio de discursos para controlar o trabalho e os corpos nas empresas (profissionalismo organizacional).

Segundo Evetts, essas duas formas de organização do trabalho baseadas em conhecimento podem ser sistematizadas em:

i. profissionalismo ocupacional, que se relaciona ao discurso construído dentro do grupo profissional, à autoridade colegiada, à discricionariedade e controle ocupacional do trabalho, à confiança no praticante por parte de clientes e empregadores, aos praticantes que operacionalizam os controles, à ética profissional monitorada por instituições e associações, localizando-se no modelo durkheimiano de comunidades morais; 
ii. profissionalismo organizacional, que se refere ao discurso de controle cada vez mais usado pelos administradores nas organizações de trabalho, às formas e à autoridade racional-legal, aos procedimentos padronizados, às estruturas hierárquicas de autoridade e decisão, ao gerencialismo, a prestar contas e ter formas externas de regulação, estabelecimento de metas e supervisão de desempenho, relacionando-se ao modelo weberiano de organização (Evetts, 2012: 7).

Assim, o tipo profissionalismo, conceituado por Eliot Freidson (2001), em contraste com o tipo burocrático ou o tipo do livre mercado, se hibridiza na concepção de Evetts, sendo usado não só pelos profissionais, mas também pelos gestores e pelas corporações. Em consonância com a tipologia proposta por esta autora - que articula a possibilidade de um profissionalismo como sentimento comum interno ao grupo, profissionalismo esse que vem de cima para baixo, como discurso de controle -, seu estudo investiga a profissionalização da carreira docente nos cursos de direito (Bonelli et alii, 2008).

Se o profissionalismo se consolidou ao longo do século XX sustentado pelo ideário de uma identidade partilhada e um ethos comum ao grupo, a produção dessa coesão é hoje uma narrativa que não se sustenta diante dos processos fragmentários objetivos e subjetivos vivenciados pelos profissionais. Mesmo que ao longo do século passado a imagem de uma identidade estável na profissão já revelasse o empenho da associação profissional na produção de tais laços, hoje a multiplicação dessas entidades e a amplitude da estratificação profissional inviabiliza tal crença.

O debate em torno das identidades sociais requer uma definição deste conceito. Ao reconhecer o problema do essencialismo e da fixação estável de pertencimentos atribuídos à identidade, a perspectiva aqui adotada foca as interações cotidianas como forma de negociação de identificações e desidentificações,

nas múltiplas maneiras de se combinar as noções de semelhança e continuidade com as noções de diferença e especificidade (Scott, 2015: 2).

O sentido do termo "identidade social" é assim negociado como a suturação de identificações (Hall, 2000), criativamente burilada e manuseada no processo de interação social. 


\section{Gênero, diferenças \\ e suas intersecções}

A maioria das análises internacionais sobre a expansão da participação das mulheres na docência do direito enfatiza a dimensão estrutural das práticas de gênero, destacando a segregação, a incorporação das mulheres em posições subalternas do meio acadêmico, a reprodução dos estereótipos de gênero da vida privada na carreira, com a concentração das professoras em disciplinas identificadas como femininas (McGinley, 2009; McGlynn, 2006; Merrit \& Reskin, 2003; Schultz, 2016; Thornton, 2015).

No Brasil, as pesquisadoras e os pesquisadores do gênero e das diferenças nas profissões jurídicas vêm construindo esse conhecimento e combatendo as discriminações. Sobre as mulheres nas carreiras jurídicas no país há uma significativa produção, que ganha mais visibilidade a partir da década de 1990. Predominam as análises sobre as mulheres na advocacia e na magistratura. Os estudos pioneiros foram os de Elias (1989) e Junqueira (1998; 1999), seguidos das contribuições de Sadek (2006), Bonelli et alii (2008), Barbalho (2008), Marques Jr. (2014), Fragale Filho et alii (2015), Campos (2018), Oliveira e Ramos (2016) e Bertolin (2017).

Ao deslocar identificações fixas e posições estáticas na produção e reprodução de saberes, gênero e diferença no mundo acadêmico do direito, buscam-se as negociações de significados que ocorrem entre os sujeitos que experimentam a vida profissional em contextos fragmentários. Como em outros campos do conhecimento, os processos globalizantes no ensino jurídico engendram formas de homogeneização na profissão, mas estas apresentam espaço suficiente para uma fragmentação articulada do mundo, reordenando diferenças e desigualdades sem erradicá-las (García Canclini, 2014).

O gênero é abordado como construção cultural e social, categoria analítica que questiona a naturalização da dualidade sexual como constitutiva da essência fixa e imutável do ser, reconhecendo que a ênfase nas diferenças anatômicas foram essencializadas em contextos históricos e culturais específicos. Tal concepção apoia-se em Joan Scott (1990), que critica a essência que se atribui à diferença física entre homens e mulheres, universalizando a dominação masculina no tempo e no espaço, destacando a dimensão relacional da categoria de gênero, focalizando a mulher nas relações sociais e culturais com outros homens e mulheres. O gênero como categoria analítica desconstruiu a concepção biologizada, mostrando como a diferença sexual é socialmente construída, em vez de ser a base da subordinação 
feminina. A autora evidenciou também como a segregação no mercado de trabaIho é parte do processo de construção binária do gênero e das relações de poder que engendravam.

Quanto à diferença, a pesquisa utiliza a conceituação de Avthar Brah (2006). Para ela, gênero e raça não são fixos nem experimentados da mesma forma pelos sujeitos, as marcas sociais não denotam sempre o sentido excludente da diferença. Assim, o diferente é negociado, ganhando novos contornos, como a diversidade e seu sentido de inclusão.

Embora as diferenças venham sendo estudadas nas organizações, a interseccionalidade entre gênero, raça e classe conjuntamente é pouco abordada (Acker, 2012). O foco na intersecção permite compreender como ela atua para reproduzir ou mudar os regimes de desigualdades, dando visibilidade ao que pode parecer imperceptível, como a distinção entre o que está em processo daquilo que já está estruturado.

\section{A pulverização institucional e a diversificação da composição docente e discente dos cursos de direito}

A fragmentação dos modelos institucionais no Brasil tem mais semelhança com os processos de massificação ocorridos em sociedades periféricas, embora tenha as características neoliberais apontadas nas análises sobre a Austrália, os Estados Unidos e o Reino Unido. Nesses países, a expansão das faculdades é significativa, mas o total de cursos é bem menor que o brasileiro. Os Estados Unidos possuem 205 escolas de direito credenciadas pela American Bar Association, num total aproximado de 250 cursos. No Brasil, em 2016, a Ordem dos Advogados do Brasil (OAB) recomendou 146 cursos, 11,3\% do total existente nesse ano (Exame da Ordem em números, 2017).

A pulverização começa pelo tipo de mantenedora (pública ou privada), passa pela categoria administrativa das instituições de ensino superior (IES) (privada sem fins lucrativos, com fins lucrativos, federal, estadual, municipal, especial), pela organização acadêmica (faculdade, centro, universidade), pela localização regional (macrorregiões), pela divisão territorial e administrativa (capital, interior) e pelo regime de trabalho (dedicação exclusiva, tempo integral, tempo parcial, horista). Ela chega ao perfil docente, com a diferenciação segundo sexo, cor/raça e grau de titulação mais elevado. 
4. Refere-se a um número pequeno de instituições que são gratuitas, mas não são públicas.
O Censo da Educação Superior do Inep, de 2015, identificou 1.107.405 matrículas nos cursos de direito no Brasil, sendo 54\% de mulheres. Do total, $67 \%$ estavam cursando, $10 \%$ haviam se formado e $23 \%$ haviam sido desvinculados. Dos 746.538 alunos que estavam cursando, $10 \%$ encontravam-se matriculados em IES públicas ou especiais ${ }^{4}$, e 46,7\% estavam nas IES privadas sem fins lucrativos e 43,3\% em IES privadas com fins lucrativos. Entre os 210.582 alunos que ingressam em 2015, $60 \%$ vinham do ensino médio público. Quanto ao gênero, 55,3\% é de mulheres. Quanto à cor/raça, a presença feminina branca/amarela é um pouco mais elevada que a masculina, com $41 \%$ para elas e $39 \%$ para eles. Observa-se a expansão constante dos discentes pretos, pardos e indígenas, mais acentuada entre os homens (30\%) do que entre as mulheres (28\%), e nas instituições privadas com fins lucrativos.

TABELA 1

DISTRIBUIÇÃO DA COR/RAÇA E SEXO DOS DISCENTES DOS CURSOS DE DIREITO INGRESSANTES EM 2015, SEGUNDO TIPO DE INSTITUIÇÃO ONDE ESTUDAM, SE CONTAM COM ALGUM FINANCIAMENTO, E SE SÃO PROVENIENTES DO ENSINO MÉDIO PÚBLICO OU PRIVADO

\begin{tabular}{|c|c|c|c|c|c|}
\hline & \multicolumn{3}{|c|}{ Cor/raça } & \multicolumn{2}{|c|}{ Sexo } \\
\hline & Branca/Amarela & Preta/ Parda/ Indigena & Sem info & Mulher & Homem \\
\hline \multicolumn{6}{|l|}{ Tipo de Ensino Superior } \\
\hline Pública & $8 \%$ & $8 \%$ & $8 \%$ & $8 \%$ & $9 \%$ \\
\hline Privada sem fins lucrativos & $55 \%$ & $41 \%$ & $36 \%$ & $46 \%$ & $44 \%$ \\
\hline Privada com fins lucrativos & $37 \%$ & $51 \%$ & $56 \%$ & $46 \%$ & $47 \%$ \\
\hline \multicolumn{6}{|l|}{ Financiamento } \\
\hline Sem financiamento & $57 \%$ & $50 \%$ & $49 \%$ & $52 \%$ & $53 \%$ \\
\hline Com financiamento & $43 \%$ & $50 \%$ & $51 \%$ & $48 \%$ & $47 \%$ \\
\hline \multicolumn{6}{|l|}{ Tipo de ensino médio } \\
\hline Privado & $43 \%$ & $33 \%$ & $42 \%$ & $40 \%$ & $41 \%$ \\
\hline Público & $57 \%$ & $67 \%$ & $58 \%$ & $60 \%$ & $40 \%$ \\
\hline $\mathrm{N}$ & 84.489 & 60.739 & 65.354 & 116.487 & 94.095 \\
\hline
\end{tabular}

O alunado de direito cursa o ensino superior principalmente no período noturno (64\%), não sendo observada diferença em termos raciais entre os diversos turnos; quanto ao gênero, embora as mulheres sejam maioria em todos os períodos, no noturno isso é menor. Os programas de reservas de vagas com recorte étnico, deficiência, proveniente de escola pública ou renda familiar atingiram menos $2 \%$ do total de discentes cursando em 2015. Dos ingressantes nesse ano, 45\% 
TABELA 2

DISTRIBUIÇÃO DO REGIME DE TRABALHO, DA MAIOR TITULAÇÃO

E DA CATEGORIA DA INSTITUIÇÃO DOS DOCENTES DOS CURSOS DE DIREITO, SEGUNDO O SEXO E A COR/RAÇA (BRASIL, 2015)

\begin{tabular}{|c|c|c|c|c|c|}
\hline & \multicolumn{2}{|c|}{ Sexo } & \multicolumn{3}{|c|}{ Cor/raça } \\
\hline & Mulher & Homem & Branca/ Amarela & Preta/ Parda/ Indígena & Sem info \\
\hline \multicolumn{6}{|l|}{ Regime } \\
\hline Horista & $23 \%$ & $28 \%$ & $28 \%$ & $26 \%$ & $21 \%$ \\
\hline Parcial & $38 \%$ & $38 \%$ & $39 \%$ & $41 \%$ & $34 \%$ \\
\hline Integral DE & $9 \%$ & $7 \%$ & $5 \%$ & $5 \%$ & $15 \%$ \\
\hline Integral sem DE & $30 \%$ & $27 \%$ & $28 \%$ & $28 \%$ & $30 \%$ \\
\hline \multicolumn{6}{|l|}{ Titulação } \\
\hline Doutor & $30 \%$ & $27 \%$ & $28 \%$ & $24 \%$ & $32 \%$ \\
\hline Especialista & $22 \%$ & $27 \%$ & $25 \%$ & $31 \%$ & $22 \%$ \\
\hline Graduado & $0 \%$ & $1 \%$ & $0 \%$ & $1 \%$ & $2 \%$ \\
\hline Mestre & $48 \%$ & $45 \%$ & $47 \%$ & $44 \%$ & $44 \%$ \\
\hline \multicolumn{6}{|l|}{ Instituição } \\
\hline Privada & $84 \%$ & $82 \%$ & $88 \%$ & $86 \%$ & $70 \%$ \\
\hline Pública & $16 \%$ & $18 \%$ & $12 \%$ & $14 \%$ & $30 \%$ \\
\hline $\mathrm{N}$ & 12.918 & 19.331 & 18.342 & 5.393 & 8.514 \\
\hline
\end{tabular}

Fonte: Bonelli, baseado em dados do Censo da Educação Superior, Inep, 2015.

recorreram aos diversos programas de financiamento estudantil, na sua maioria públicos.

No tocante às disciplinas do curso de direito, o Censo da Educação Superior de 2015 encontrou 32.249 docentes, sendo $60 \%$ homens. Não há informação sobre cor/raça para $26,4 \%$ do universo, mas $57 \%$ é branco ou amarelo e $16 \%$ é preta, parda ou indígena. Embora o doutorado venha crescendo entre esses profissionais, apenas $27 \%$ dos homens e $30 \%$ das mulheres possuem esse grau de titulação, predominando o mestrado para ambos. O quadro de professores nas instituições públicas é de 5.489, $17 \%$ do total, havendo mais homens do que mulheres, sendo mais acentuada aí a presença de doutores. Também são essas instituições que concentram os docentes em tempo integral e dedicação exclusiva. Nos últimos cinco anos, há uma tendência de redução na porcentagem de docentes no regime de trabalho horista, distribuindo-se pelo regime de tempo parcial e o integral sem dedicação exclusiva.

Embora os docentes pardos, pretos e indígenas representem o menor montante no grupo, eles estão proporcionalmente bem nas instituições públicas e entre aqueles 


\section{GRÁFICO 1}

DISTRIBUIÇÃO DOS DOCENTES E DISCENTES DOS CURSOS

DE DIREITO NO BRASIL, SEGUNDO O SEXO E A COR/RAÇA (BRASIL, 2015)

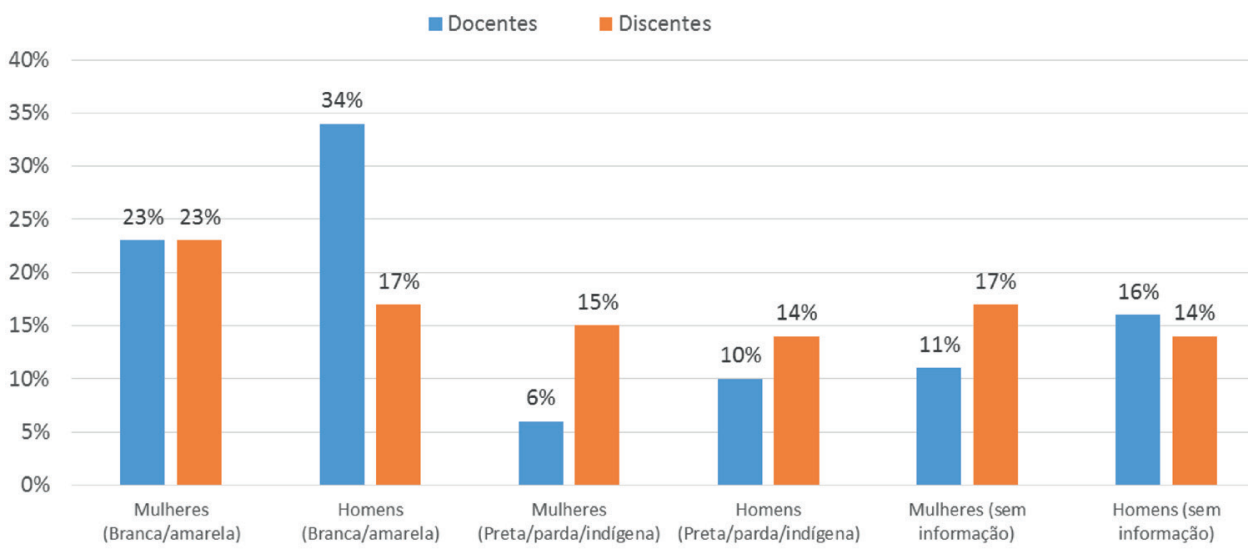

Fonte: Bonelli, baseado em dados do Censo da Educação Superior, Inep, 2015

com titulação de mestrado, mas encontram-se sobrerrepresentados entre os especialistas e docentes em regime de tempo parcial.

Há expressiva concentração de homens brancos na docência, se comparada com a proporção deles no alunado (34\% a 17\%). A porcentagem de mulheres brancas é a mesma entre professoras e alunas (23\%).

Ao considerarmos a intersecção entre o gênero e a cor/raça, observamos que o grupo dos homens brancos deixa de ter a hegemonia na composição do corpo

TABELA 3

DISTRIBUIÇÃO DOS DOCENTES E DOS DISCENTES SEGUNDO A CATEGORIA ADMINISTRATIVA

DOS CURSOS DE DIREITO*

\begin{tabular}{|l|c|l|}
\hline Categoria Administrativa & Docentes & Discentes \\
\hline Privada com fins lucrativos & $31 \%$ & $43,3 \%$ \\
\hline Privada sem fins lucrativos & $36 \%$ & $46,7 \%$ \\
\hline Pública /Especial & $32 \%$ & $10,0 \%$ \\
\hline N & 33.873 & 746.538 \\
\hline
\end{tabular}

* O total de docentes foi extraído da planilha do Inep sobre os cursos, e não da planilha sobre os docentes. Assim, o total é superior ao das outras tabelas pelo fato de o mesmo docente dar aulas em mais de um curso/IES. O total de alunos refere-se aos que estavam matriculados em 2015, excluindo-se os desvinculados e os formados.

Fonte: Bonelli, baseado em dados do Censo da Educação Superior, Inep, 2015. 
docente. Excluindo os casos sem informação para cor/raça, em 2009 os homens brancos eram 50\% e em 2015 os homens brancos/amarelos são 46,6\%.

A distribuição dos docentes e discentes pelas categorias administrativas das IES revela a disparidade na concentração de alunos de graduação no sistema privado de ensino, enquanto os docentes estão relativamente bem distribuídos entre privadas com fins lucrativos, privadas sem fins lucrativos e públicas/especiais.

Observa-se o maior investimento na constituição de um modelo acadêmico para a docência do direito que vai se ampliando perante o padrão majoritário do profissional com experiência prática. Isso resulta de controles do Ministério da Educação sobre a qualidade dos cursos e de seus docentes, como também da concorrência por alunos no mercado do ensino jurídico. A carreira acadêmica no direito que hoje se globaliza é mais evidente nas universidades públicas, que, entre 2009 e 2015, saíram de $29 \%$ de docentes com doutorado para 40\%. O esforço das IES privadas neste sentido também é observado, partindo de $12 \%$ para $26 \%$ no mesmo período.

Com a propagação do ensino jurídico, a docência tem se tornado um mercado de atuação profissional. As carreiras acadêmicas vêm se ampliando associadas aos 106 Programas de Pós-Graduação stricto sensu existentes no Brasil, em 2016. Eles ofereceram 137 cursos, sendo 34 de doutorado. Segundo dados fornecidos pela Coordenação de Aperfeiçoamento de Pessoal de Nível Superior (Capes), em 2015, dos 2.159 docentes dos programas de pós-graduação em direito, 71\% eram homens. Os alunos matriculados nos cursos de mestrado em direito, em 2015, somavam 8.360 (58\% homens) e nos cursos de doutorado eram 2.933 (61\% homens). Em estudo sobre a nucleação acadêmica dos programas de pós-graduação em direito, Marcelo Varella (2017) procurou identificar a procedência institucional do maior grau de titulação dos docentes, analisando o universo de professores existente no sistema de dados da Capes, Ministério da Educação, de 2012. Sua conclusão é que no Brasil nenhum programa exerce de fato a nucleação, já que nenhuma instituição tem predominância nacional, havendo em cada região uma escola que detém essa influência, com recrutamento endógeno dos docentes entre seus egressos (Varella, 2017: 124).

\section{Docência do direito:}

sujeitos da pesquisa e a categorização das identificações

Este tópico apresenta uma síntese do trabalho de campo extraída das primeiras análises das entrevistas realizadas com o objetivo de elaborar uma tipologia que articule as identificações e os descentramentos. 
5. O trabalho de campo com IES que visam fins lucrativos ainda não foi iniciado, sendo a próxima etapa da pesquisa.
Dos docentes entrevistados, 33 são homens e 20 mulheres. Quanto às instituições nas quais eles e elas atuam, as entrevistas foram feitas em duas IES localizadas em capitais do Nordeste, duas em capitais do Sudeste, uma em cidade da Região Sul fora da capital, uma em capital do Centro-Oeste. Dessas seis IES, duas são públicas e quatro privadas sem fins lucrativos, uma delas é de grande porte e as outras três são geridas por mantenedoras pequenas 5 . Dos até agora 53 entrevistados, 28 estão em IES que oferecem cursos de mestrado e doutorado e os demais em IES que só oferecem graduação, podendo ter pós-graduação lato sensu.

A distribuição do grupo quanto à faixa etária é bem variada, indo dos 26 aos 71 anos, mas concentra-se entre 30 e 49 anos; quanto à raça/cor predominam os brancos, havendo na amostra 36\% de docentes pardos e pretos. A autodeclaração de cor "brasileira" apareceu tanto nas entrevistas no Nordeste quanto no Sudeste e no Sul. Houve também a situação de dois entrevistados no Nordeste que se declararem negro e cafuzo por serem contra a política de ação afirmativa, embora se considerassem brancos. A indagação sobre a sexualidade foi motivo de surpresa ou dificuldade de compreensão da pergunta em várias entrevistas, mas quase todas se declararam heterossexual e raras vezes houve a opção de não responder à questão.

O grau de titulação também é bastante diverso, havendo casos de o maior título ser a graduação, a especialização, o mestrado, o doutorado e a livre-docência. Entrevistados(as) mencionaram a posição de docente titular, de pós-doutorado, de bolsa produtividade do Conselho Nacional de Desenvolvimento Científico e Tecnológico (CNPq). Houve casos de jovens docentes com elevada titulação e de docentes mais idosos apresentando a graduação como grau mais elevado ou a especialização. Também encontramos essa diversidade em IES pública.

A remuneração mensal como professor apresentou bastante variação, já que do regime de trabalho horista à dedicação exclusiva encontramos docentes recebendo menos de $\mathrm{R} \$ 2.000$ e outros com até $\mathrm{R} \$ 20.000$. A renda mensal no conjunto das atividades teve uma amplitude bem maior, com professores que têm a docência como única ocupação, disputando turmas com colegas para sua remuneração total ficar entre $R \$ 2.000$ e $R \$ 5.000$ e alguns ganhando acima de $R \$ 40.000$. As dificuldades de manter o número de turmas nessas IES menores surgiram com a perda de financiamento público, como o Fundo de Financiamento Estudantil (Fies), que resultou em mais acentuada evasão discente e em problemas de caixa dessas instituições privadas. Além disso, esses estabelecimentos enfrentam forte concorrência das IES com mantenedoras corporativas lucrativas, que "prospectam" alunos de outras faculdades para transferência com menor mensalidade. O impacto 
na oferta de disciplinas é significativo, sendo mais acentuado entre as optativas, com perda de turmas e redistribuição interna de uma grade mais apertada.

A motivação para atividade docente aparece como fator de satisfação, de prazer, gosto, de escolha natural, vocação na grande maioria dos depoimentos, mas vários entrevistados não têm a docência como atividade principal e, embora se sintam sobrecarregados, não querem abrir mão dela, assim como não pretendem dedicar-se exclusivamente a ela. Várias narrativas enfatizaram como ser professor é formar pessoas, contribuir para que os estudantes tenham uma visão mais ampla e tomem contato com a realidade para além dos códigos. A docência chega a parecer uma atividade lúdica em comparação às demais ocupações, seja de advogado, procurador, juiz, promotor, defensor, servidor judiciário, servidor público, assessor jurídico, de relações governamentais, oficial da polícia, delegado.

No decorrer das conversas, lecionar vai se revelando como uma forma de construir redes, de ampliar a visibilidade e a respeitabilidade profissional na atividade principal, de ter prestígio e reconhecimento. Fala-se também em vaidade. Alguns se referiram à época em que a docência era bico para complementar renda, dando a entender que hoje a realidade é diferente. Em termos materiais, ser professor significa maior capacidade de atrair clientes e isso não é exclusividade das IES mais bem avaliadas. Em instituições que recebem alunos de origens sociais mais desfavorecidas, também se consegue cliente pela indicação deles, na área do direito civil, trabalhista, penal. A estratificação social se manifesta nas diferentes oportunidades que podem ser mobilizadas pelos docentes como também nos constrangimentos à sua ação. Há docentes que difundem seus livros, recebendo direitos autorais, além do salário como docente e de sua remuneração na outra ocupação. Há docentes que efetivamente necessitam da complementação salarial da docência para sua manutenção, já que a renda da outra atividade é insuficiente. Existem professores em dedicação exclusiva à docência, em IES com carreiras estruturadas e regras definidas de progressão e remuneração. Outros são exclusivamente docentes, mesmo em regime de trabalho horista ou tempo parcial, e precisam enfrentar a disputa por turmas para pagar suas contas.

A tipologia das identificações docentes que esta pesquisa sugere é construída mapeando as disputas por legitimação que eles e elas travam cotidianamente com seus pares. Embora o Ministério da Educação, a Capes, o CNPq, a OAB definam regras de avaliação, produzindo "juízos" sobre as hierarquias docentes, a legitimidade desses profissionais não se reduz aos valores e à autoridade dessas instituições. Em vez da concepção weberiana do mando da autoridade legítima, a perspectiva analítica é a da legitimidade como conflitos decorrentes da plura- 
lidade de valoração, como espaços de ação criativa nos quais os professores e as professoras produzem estratégias de legitimação por meio dos embates morais.

Tais enfrentamentos retóricos são parte relevante do jogo para produzir os centros e para descentrar os grupos estabelecidos e o cânone jurídico. Em vez de um centro estático, encontra-se a produção de centros que escapam a essa fixidez, a partir das interações e dos lugares de fala dos sujeitos. Eles também se veem simultaneamente em posições centradas e descentradas dependendo da forma como significam as situações nas quais se reconhecem ocupando postos que geram competição ou desvalorização, diferenciando-se da concepção que estabelece um centro a difundir sua influência para a periferia. Assim, sugere-se a seguinte categorização das identificações na docência do direito, sintetizando as narrativas registradas:

1. Produção da identificação docente como centro: profissão como núcleo identitário, fornecendo as principais referências em termos de subjetividade, sintonia com o ideário do profissionalismo e da excelência, saber predomina sobre diferenças. Descentrar, neste caso, refere-se ao deslocamento do ensino tradicional por meio de novas metodologias, de tecnologias online, de participação de alunos, da produção de pesquisas, da atualização de conteúdos disciplinares em decorrência de mudanças na legislação e no conhecimento canônico.

2. Produção da identificação docente descentrada em relação ao cânone: a desconstrução dos conteúdos estabelecidos, a difusão de saberes situados nas fronteiras do campo focaliza o direito pelas perspectivas das minorias e dos desfavorecidos valoriza a influência das políticas de ação afirmativa na universidade, podendo se suturar às intersecções identitárias. Descentrar é pluralizar numa perspectiva crítica, emancipatória, que se articula à presença da diferença na docência, mesmo que a narrativa seja de professor com outra ocupação além da acadêmica, hétero, branco, de origem social favorecida.

3. Lutas por identificação não estabelecidas, embates morais em busca de reconhecimento dos pares: conflitos pela produção de novas identidades (como a que afirma a pesquisa empírica em direito em contraste ao ensino dogmático); alteridade entre carreira exclusivamente acadêmica e a docência como reflexo da posição bem-sucedida fora da universidade. Descentrar relaciona-se às mudanças decorrentes dos embates e deslocamentos de grupos de poder profissional, à fluidez de centros que escapam à sua fixação. 
4. Construção da identificação interseccional (entrecruzamento da identidade docente com a de gênero, cor/raça, classe, geração, religião): a identidade profissional sutura-se a outras como o pertencimento racial, os cuidados com a família, as experiências de preterimento e discriminação decorrentes das diferenças, mas sem acentuar a crítica à dogmática jurídica. Descentrar é combinar essas identificações antes ausentes, deslocando mais a composição do grupo do que do cânone.

5. Processos de desidentificação: as percepções daqueles que estão se distanciando ou saindo da atividade para priorizar outra ocupação ou a aposentadoria. Descentrar decorre desse afastamento produzindo novas identificações fora da docência do direito ou da vida profissional ativa.

Anselm Strauss (1999: 37) abordou como a identidade torna-se central quanto mais os sujeitos se empenham e se dedicam a ela, considerando-a como um esforço pessoal e um empreendimento compartilhado, vinculando o compromisso com o senso de identidade. Stuart Hall (2005: 21) conceituou o "jogo de identidades" concebendo-as como contraditórias, na qual nenhuma predomina sobre as demais. Segundo ele, a interseccionalidade e a fragmentação contemporâneas erodiram a ideia de uma identidade mestra - como a identidade de classe - fraturada pela constante interpelação dos sujeitos, confrontados pela multiplicidade de identificações, podendo ser conquistadas ou dissipadas ao longo da vida.

A docência do direito revela-se uma combinação particular desse "jogo de identidades", no qual o esforço e o tempo dedicados à atividade docente nunca podem ser "os mesmos", "idênticos", pela existência ou não de vínculos com outra ocupação. Assim, estar nesse centro depende mais da ênfase no empreendimento compartilhado que tenta gerar um "senso de identidade" entre esses empenhos distintos. O compartilhamento é fragmentado pela diversidade de posições profissionais a interpelar os sujeitos que cotidianamente se deparam com os pares em outros trabalhos, como pelas disputas com os colegas de dedicação exclusiva à carreira acadêmica, sendo parte relevante do jogo em torno dessas identificações.

Os pares que ocupam a gestão da faculdade costumam invocar, a partir deste lugar de fala, a "mesma" identidade para os colegas de dedicação exclusiva e os que acumulam docência com outras ocupações, procurando mediar as competições no ambiente acadêmico, acentuadas na pós-graduação. Assim, observa-se nas narrativas de coordenadores e chefes o empreendimento moral ao negociar o sentido sobre os vínculos profissionais "de fora" incorporados como "de dentro", como capital simbólico que valoriza o ensino, a expertise e a produção do 
conhecimento. Neste aspecto, é uma atribuição de identidade que visa reduzir os conflitos e criar alguma coesão. As disputas morais sinalizam as dificuldades para isso se constituir como sentimento compartilhado pelos docentes, haja vista a alteridade e a pluralidade dos movimentos de suturação das identificações.

Por outro lado, além da pesquisa encontrar a produção de identidades centradas em sujeitos de posições deslocadas, observou o inverso: discursos descentrados construídos na pós-graduação de excelência, em concorrência com as visões estabelecidas nesses espaços de poder. As identificações descentradas em relação ao cânone vieram de homens e mulheres, brancos ou não, exercendo a docência na graduação e/ou na pós-graduação. Se os paradigmas dominantes circulam amplamente nos espaços fragmentários do ensino jurídico, sua crítica se faz presente nos diferentes modelos institucionais, regimes de trabalho e regiões de atuação. Na pós-graduação, os sentidos do descentramento do cânone mediavam a relevância da excelência com outros fatores deslocados da perspectiva autorreferida à dogmática jurídica.

Um aspecto que dá fluidez à percepção centrada e descentrada dos docentes refere-se à valorização junto ao alunado dos professores com outras carreiras jurídicas de prestígio. Isso gera sentimentos de desvalorização naqueles de dedicação exclusiva, inclusive na pós-graduação, vista com frequência como espaço central de atuação.

Nesses programas, a métrica da titulação mais elevada e da produção acadêmica extensa é considerada a forma de avaliação e de reconhecimento, gerando deferência, competição e contestação, tanto internamente quanto nas margens, entre aqueles que esperam ingressar ou que se opõem a tais medidas. Ainda mais recente na luta por legitimação é a realização de pesquisa empírica como critério diferencial dessa produção. Os docentes homens e mulheres que valoram outras qualidades - como a excelência na experiência profissional extra acadêmica, a gestão institucional, a capacidade pedagógica e a boa avaliação entre os alunos - resistem ao predomínio da métrica estabelecida. Houve, em entrevistas, ironia na forma de se falar sobre os docentes afinados com as regras em vigor para o credenciamento na pós-graduação. Indicativo do discurso normásculo presente nessa disputa é a brincadeira que desqualifica os professores que entram no embate com sua produção, como se o Currículo Lattes fosse o "pênis acadêmico", relacionado às medidas da virilidade.

Já naquelas IES que oferecem o curso de graduação e o lato sensu, as fontes de conflito entre os colegas são outras, como os ganhos com os cursos de extensão, a obtenção de mais carga de aulas - e em resistência a isso - a preservação de uma 
disciplina que outro docente está pleiteando, o horário das aulas, principalmente quando envolve deslocamento entre cidades, a competição pela oferta de atividades de extensão que atraem inscrições e a visibilidade. Os postos de coordenação e gestão são considerados importantes, produzindo distinção, embora estejam fora do âmbito da disputa, por resultar de laços do profissional com a mantenedora, que decide quem o preenche. Há insatisfação com as mantenedoras por direitos trabalhistas, pagamento de horas, depósito de FGTS, reconhecimento da titulação mais elevada no salário, vigilância de bedel sobre o docente, anulação de faltas discentes na lista de presença com o pagamento de multas, aceitação de matrícula na disciplina depois de meses de iniciadas as aulas, entre outras situações que fraturam a condição profissional.

Nos cursos de graduação em direito com ingresso mais facilitado em termos de desempenho discente, comunicar-se com as turmas, ser compreendido, é um diferencial. Há casos de abaixo-assinados para tirar professores que os alunos "não entendem", cujo conteúdo da aula é considerado muito teórico e pouco prático. Exercer uma profissão jurídica, além do ensino, gera admiração e legitimidade maior do que ter titulação mais elevada, até mesmo porque certos estabelecimentos não reconhecem essa qualificação no valor da hora aula. Nesses casos, a supervisão do Ministério da Educação (MEC) e as visitas à IES ajudam os docentes, que mesmo tendo a princípio mais facilidade de acesso à Justiça, na prática do trabalho docente perdem direitos com salários atrasados, alteração nos cálculos das horas, falta de depósito do fundo de garantia para fins de desemprego, maternidade, aposentadoria.

A distância social entre o topo da pirâmide no ranking dos programas de pós-graduação e a base nesses cursos de graduação dá visibilidade a essa forma de desigualdade. O mundo desses graduandos é muito distante das disputas entre os docentes do doutorado, mas o fato de os discentes valorizarem o sucesso profissional fora da vida acadêmica, produz uma agência conjunta que influencia os processos de legitimação do professorado, como produto dos valores em conflito. Mesmo entre os docentes dos cursos de graduação das pequenas mantenedoras, observam-se as barreiras de acesso a esses títulos. Vários tentam admissão, não obtêm aprovação na pós-graduação da IES pública e seus rendimentos não são suficientes para custear o mestrado ou doutorado em IES privada. Esses docentes, principalmente os jovens, valorizam a titulação mais elevada.

A identificação e a percepção da diferença aparecem relacionadas em algumas entrevistas, sendo vividas como excludentes ou não. Houve depoimentos nos quais as marcas de cor/raça ou gênero não foram relatadas pelo/a entrevistado/a 
como fatores de preconceito na docência, mas divergentes disso, colegas coordenadores mencionaram situações que discriminavam tais docentes, como alunos procurando a coordenação para pedir transferência de turma - fato associado ao racismo -, professora sendo retirada da disciplina e substituída por professor sem receber nenhuma comunicação da direção. Várias docentes mencionaram a intersecção entre gênero e geração, para apontar situações de desrespeito em sala de aula, inclusive no caso de um aluno que se sentou na fileira da frente para fotografar as pernas da professora e postar no WhatsApp da turma.

A intersecção da identificação profissional e racial foi mencionada na forma como docentes enfatizam a visibilidade de sua presença na sala de aula, sua projeção como referência e possibilidade de êxito acadêmico em especial para as alunas e os alunos negros, e na desconstrução dos estereótipos sobre as minorias, inclusive daquele sobre quem comete crime. Também se revela na articulação do programa da disciplina com o tema do racismo, das discriminações e da concepção do direito como técnica de transformação social, vista pela perspectiva do lugar subalterno, discutindo conteúdos além dos códigos, trazendo diferentes leituras da realidade e da desigualdade social.

A experiência do racismo na docência foi compartilhada no relato do professor que é confundido com o segurança do estabelecimento, na solicitação para que o docente ligue o projetor, atividade regularmente realizada naquele estabelecimento pelo pessoal de apoio. Ocorreu de forma ostensiva no caso de um aluno que escreveu a suástica nazista na prova e em xingamentos racistas feitos por estudantes pelas costas do professor. Há também a crítica ao conteúdo da disciplina por não se ater ao que cai em concursos públicos ou no exame da Ordem.

No jogo de identidades, há entrevistas que relatam a percepção da profissão como núcleo do sujeito, costurando as narrativas profissionais como mérito e agência criativa resultante da dedicação pessoal a ponto de apagar marcas da diferença. Nesses casos, elas permanecem na subjetividade e a experiência é vivida como "neutra", tendo como referência a perspectiva dominante. Essa é a visão de uma docente que não considera que o gênero influencie na obtenção de posições profissionais. Por outro lado, ela percebe muito mais como a indicação abre portas na profissão, e como ter conhecidos que the apresentam é decisivo para isso. Segundo essa professora, sua postura profissional não foi interseccionada pelo gênero, porque ela estava disposta a se dedicar totalmente ao trabalho, como fazem os homens. As normas profissionais produzidas no masculino estão presentes entre homens e mulheres, revelando a força binária dessa construção. 


\section{Considerações finais}

O artigo aborda as mudanças na docência do direito com base em dados do Censo da Educação, que confirmam a pulverização institucional, a fragmentação profissional e a diversificação do corpo docente. Relaciona esse quadro com os novos discursos do profissionalismo e do gerencialismo no mundo do direito, resultando em lógicas hibridizadas no profissionalismo organizacional. A luta concorrencial com o profissionalismo ocupacional desloca a profissão de sua posição fixa e central nas experiências e identificações de seus membros.

Os dados mostram que essa docência é exercida por um grupo diversificado quanto à inserção profissional e social que leciona para um corpo discente muito desigual quanto às origens e oportunidades. A pós-graduação stricto sensu surge como o principal diferenciador a produzir os enfrentamentos retóricos internos ao professorado. Nas instituições privadas, a direção aparece como a instância geradora dos conflitos sobrepondo-se às relações inter pares.

Quanto ao alunado, a distância social entre a base da pirâmide dos cursos de graduação e o topo do ranking dos cursos de pós-graduação parece constituir mundos sociais que não se comunicam, fortalecendo as disputas para legitimar os professores que dominam a prática como profissionais do direito e comunicam esses conteúdos, dando menos valor aos critérios da excelência acadêmica reconhecidos pela Capes. Essa pluralidade de valores, que se manifestam em embates morais, atua para descentrar as identificações profissionais, já fragmentadas pelo hibridismo no ideário do profissionalismo e pela lógica empresarial.

A análise preliminar das entrevistas possibilitou sugerir uma tipologia das identificações dos docentes vinculada às formas como são negociados os sentidos do centrar e descentrar as identidades e os cânone jurídico.

A produção dessa centralidade não é fixa, movendo-se junto com os lugares de fala, podendo revelar-se como um empreendimento coletivo que atribui a identidade comum docente aos profissionais deslocados pelos vínculos extra acadêmicos. Esses sujeitos são interpelados de "dentro" e de "fora" da universidade para assumirem identificações com ocupações concorrentes, que eles precisam manusear e suturar. De outro lugar, registrou-se a crítica feita por professores de dedicação exclusiva à centralidade atribuída aos profissionais que exercem simultaneamente outra ocupação jurídica. Nessa visão, trazer para dentro das faculdades de direito o poder e o prestígio profissionais externos borra as fronteiras 
acadêmicas. Resulta assim a construção do "nós" e "eles", a alteridade identitária no professorado e o discurso descentrado se constituindo como nova força.

As narrativas revelam como essas suturas não constituem blocos recortados por uma clivagem predominante, uma identidade mestra articulando as demais. Assim, há docentes que exercem outra ocupação, mas se identificam com a excelência acadêmica na pós-graduação e com a desconstrução do cânone jurídico.

Se a pós-graduação for tomada como um centro, é neste degrau da carreira que a diversidade dos marcadores sociais entre os professores é menor, com predominância masculina. As entrevistas realizadas apontam para a maior participação das mulheres e dos docentes não brancos na graduação, com rendimentos menores do que o dos professores credenciados no mestrado e doutorado. O topo do segmento acadêmico tem controles de entrada que tornam o acesso mais fácil para aqueles com as características sociais privilegiadas.

A incorporação das mulheres e da diferença na docência do direito diversificou o grupo, interseccionou as identificações reverberando nos embates para a produção dos centros e dos descentramentos, mas isso não reduziu as desigualdades. A estratificação baseada no gênero, cor/raça e classe acentuou-se com o processo fragmentário na educação superior e o descolamento da pós-graduação em relação à graduação, em que a mercantilização do ensino fraturou mais a autonomia do profissionalismo.

\section{Referências}

ACKER, Joan. Gendered organizations and interseccionality: problems and possibilities. Equality, Diversity and Inclusion: An International Journal, v. 31, n. 3, p. 214-224, 2012.

BARBALHO, Renne M. A feminização das carreiras jurídicas e seus reflexos no profissionalismo. Tese (Doutorado em Sociologia) - Programa de Pós-Graduação em Sociologia, Universidade Federal de São Carlos (UFSCar), São Paulo, 2008.

BERTOLIN, Patricia Tuma Martins. Mulheres na advocacia: padrões masculinos de carreira ou teto de vidro. Rio de Janeiro, Lumen Juris, 2017.

BONELLI, Maria da Gloria; CUNHA, Luciana G.; OLIVEIRA, Fabiana L.; SILVEIRA, Maria Natália B. Profissionalização por gênero em escritórios paulistas de advocacia. Tempo Social, v. 20, n. 1, p. 265-290, Jun. 2008. 
BRAH, Avthar. Diferença, diversidade e diferenciação. Cadernos Pagu, n. 26, p. 329-376, Jan/Jun 2006.

BUTLER, Judith. Problemas de gênero: feminismo e subversão de identidade. Rio de Janeiro: Civilização Brasileira, 2003.

CAMPOS, Veridiana. O processo de feminização da magistratura no Brasil: mecanismos e possibilidades de uma mudança social [e-book]. Recife, UFPE, 2018. Disponível em https: <//www3.ufpe.br/editora/UFPEbooks/Serie_Sociologia/processo_feminizacao_magistratura_BR/>.

CAOVILLA, Maria Aparecida L.; FAGUNDES, Lucas M. (Orgs.). Temas sobre constitucionalismo, interculturalidade e pluralismo jurídico na América Latina [e-book]. São Leopoldo (RS): Karywa, 2016.

CHABAUD-RYCHTER, Danielle; DESCOUTURES, Virgine; DEVREUX, Anne-Marie; VARIKAS, Eleni (Orgs). O gênero nas ciências sociais. São Paulo: Editora Unesp, 2014.

CONNELL, Raewyn. A iminente revolução da teoria social. Revista Brasileira de Ciências Sociais, v. 27, n. 80, p. 9-20, Out. 2012.

Glass ceilings or gendered institutions? Mapping the gender regimes of public sector worksites. Public Administration Review, v. 66, n. 6, p. 847-849, Nov./ Dec. 2006.

DEO, Meera E. Unequal profession: race and gender in legal academia. California: Stanford University Press, 2019.

ELIAS, Roseli. Mulher e advocacia: Elementos de ideologia e trabalho. Dissertação (Mestrado em Sociologia) - Instituto Universitário de Pesquisas do Rio de Janeiro (luperj), Rio de Janeiro, 1989.

EVETTS, Julia. Professionalism: value and ideology, 2012. Disponível em: <http:// www.isa-sociology.org/publ/sociopeda-isa>. Acesso em: 05 Mar. 2014.

EXAME DE ORDEM EM NúMEROS. Volume III, 2016. Disponível em: <http://fgvprojetos.fgv.br/sites/fgvprojetos.fgv.br/files/oab_3_edicao_v4_web_espelhado. pdf>. Acesso em: 02 Nov. 2017.

FEFERBAUM, Marina; GHIRARDI, José Garcez (Orgs.). Ensino do direito para um mundo em transformação. São Paulo : Fundação Getulio Vargas, 2012.

FRAGALE FILHO, Roberto; MOREIRA, Rafaela; SCIAMMARELLA, Ana Paula. When seniority breaks up the glass ceiling: women judges as court administrators in Brazil. Seattle (WA): Law and Society Association Meeting, 2015. 
FREIDSON, Eliot. Professionalism, the third logic. Cambridge (UK): Polity Press, 2001.

GARCÍA CANCLINI, Néstor. Imagined globalization. Durhan (NC): Duke University Press, 2014.

GELLER, Rodolfo Hans. OAB recomenda. 4. ed. Brasília: Conselho Federal da Ordem dos Advogados do Brasil, 2012. Disponível em: <https://www.oab.org.br/ arquivos/pdf/Geral/Programa_OAB_Recomenda.pdf>. Acesso em: 20 Out. 2017.

GHIRARDI, José G.; FEFERBAUM, Mariana (Orgs.). Ensino do direito em debate : reflexões a partir do I Seminário Ensino Jurídico e Formação Docente. São Paulo: Direito GV, 2013.

HALL, Stuart. A identidade cultural na pós-modernidade. Rio de Janeiro: DP\&A, 2005.

- Quem precisa de identidade? In: SILVA, Tomaz Tadeu (Org.). Identidade e diferença: a perspectiva dos estudos culturais, p. 103-133. Petrópolis (RJ): Vozes, 2000.

JUNQUEIRA, Eliane. B. A profissionalização da mulher na advocacia (Relatório de pesquisa). Rio de Janeiro: Fundação Carlos Chagas, 1999.

— A mulher juíza e a juíza mulher. In: BRUSCHINI, C.; HOLANDA, H. B. Horizontes plurais: Novos estudos de gênero no Brasil, p. 135-162. São Paulo: Fundação Carlos Chagas; Editora 34, 1998.

MARQUES JR. Gessé. Espaço, profissões e gênero: mobilidade e carreira entre juízes e juízas no estado de São Paulo. Cadernos Pagu, n. 43, p. 265-297, Jan./Jun. 2014.

MCGINLEY, Ann C. Reproducing gender on Law Schoolsfaculties. Brigham Young University Law Review, n. 1, p. 99-155, 2009.

MCGLYNN, Clare. Women, representation and the legal academy. Legal Studies, v. 19, n. 1, p. 68-92, Apr. 2006.

MERRIT, Debora Jones; RESKIN, Barbara. New directions for women in legal academy. Journalof Legal Education, v. 53, n. 4, p. 489-495, 2003.

NEDER CEREZETTI, Sheila Christina et alii. Interações de gênero nas salas de aula da Faculdade de direito da USP: um currículo oculto? São Paulo: Cátedra Unesco de Direto à Educação/Universidade de São Paulo (USP), 2019. 
OLIVEIRA, Fabiana L.; RAMOS, Luciana. Os diretores jurídicos e os advogados corporativos: carreiras em ascensão no mundo profissional do direito. In: BONELLI, M. G.; SIQUEIRA, W.L. Profissões republicanas: experiências brasileiras no profissionalismo, p. 107-144. São Paulo: EdUFSCar/Fapesp, 2016.

OBSERVATÓRIO DO ENSINO DO DIREITO. Ensino Superior 2012 - Instituições, Quem oferece os cursos de direito no Brasil. FGV Direito SP, v. 2, n. 1, 2014. Disponível em: <direitosp.fgv.br/observatório-ensino-direito>. Acesso em: 15 Jul. 2015.

SADEK, Maria Tereza. Magistrados: uma imagem em movimento. Rio de Janeiro: FGV Editora; FGV Direito Rio, 2006.

SCHULTZ, Ulrike. Gender and careers in the legal academy, 2016. Dsiponível em: <https://www.fernuni-hagen.de/videostreaming/rewi/ls_haratsch/20160621.sht$\mathrm{ml}$. Acesso em: 20 Out. 2016.

SCOTT, Joan. Gênero: uma categoria útil para a análise histórica. Revista de Educação e Realidade (Gênero e Mulheres), v. 16, n. 2, p. 5-22, Jul./Dez. 1990.

SCOTT, Susie. Negotiating identity: symbolic interactionist approaches to social identity. Cambridge (UK): Polity Press, 2015.

SOMMERLAD, Hilary. The "social magic" of merit: diversity, equity, and inclusion in the English and welsh legal profession. Fordham Law Rev, N. 83, p. 2325-2347. Sep./Oct. 2015. Disponível em: <http://ir.lawnet.fordham.edu/flr/vol83/iss5/7>. Acesso em: 10 Set. 2015.

STRAUSS, Anselm. Espelhos e máscaras: em busca da identidade. São Paulo: EdUSP, 1999.

THORNTON, Margaret. The changing gender regime in the neoliberal legal academy, 2015. Disponível em: <http://papers.ssrn.com/sol3/papers.cfm?abstract_ id=2482926 $>$. Acesso em. 10 Nov. 2015.

VARELLA, Marcelo. Quem influencia a pós-graduação em direito no Brasil? Uma análise empírica da nucleação acadêmica. Revista de direito Brasileira, v. 12, n. 5, 2015. Disponível em: <http://www.rdb.org.br/ojs/index.php/rdb/article/ view/213>. Acesso em: 29 Mar. 2017.

VERONESE, Alexandre; FARRANHA, Ana Claudia; FELIX, Loussia. Anais do X Congresso Nacional do Ensino do Direito e do VII Seminário Nacional de Ensino Jurídico e Formação Docente. Brasília: Associação Brasileira de Ensino do Direito (Abedi), 2018. Disponível em: <https://docplayer.com.br/129477473-Abedi-associacao-brasileira-de-ensino-do-direito.html>. Acesso em: 10 Abr. 2019. 
WOLKMER, Antonio C.; LIPPSTEIN, Daniela. Por uma educação latino-americana em direitos humanos: pensamento jurídico crítico contra-hegemônico. Revista de direitos e Garantias Fundamentais (FDV), v. 18, p. 283-301, 2017. 